comBÈs Isabelle, De la una y otro banda del río Paraguay: historia y etnografia de los itatines (siglos XVIXVIII)

Instituto Latinoamericano de Misiología/Itinerarios Editorial (Colección Scripta autochtona, 15), Cochabamba, 2015, 231 p., bibliogr., ill. en coul. et en noir et blanc, cartes.

\title{
Pablo Barbosa
}

\section{(2) OpenEdition Journals}

\section{Edição electrónica}

URL: https://journals.openedition.org/jsa/14716

DOI: 10.4000/jsa. 14716

ISSN: 1957-7842

\section{Editora}

Société des américanistes

\section{Edição impressa}

Data de publição: 31 outubro 2016

Paginação: 216-218

ISSN: 0037-9174

Refêrencia eletrónica

Pablo Barbosa, " combès Isabelle, De la una y otro banda del río Paraguay: historia y etnografia de los itatines (siglos XVI-XVIII) », Journal de la Société des américanistes [En ligne], 102-1 | 2016, mis en ligne le 05 décembre 2016, consulté le 04 septembre 2022. URL : http://journals.openedition.org/jsa/14716 ; DOI : https://doi.org/10.4000/jsa.14716

Este documento foi criado de forma automática no dia 4 setembro 2022.

Tous droits réservés 
comBÈs Isabelle, De la una y otro banda del río Paraguay: historia y etnografia de los itatines (siglos XVIXVIII)

Instituto Latinoamericano de Misiología/Itinerarios Editorial (Colección Scripta autochtona, 15), Cochabamba, 2015, 231 p., bibliogr., ill. en coul. et en noir et blanc, cartes.

\section{Pablo Barbosa}

\section{REFERÊNCIA}

COMBÈs Isabelle, De launa y otro banda del río Paraguay: historia y etnografia de los itatines (siglos xvi-xviii), Instituto Latinoamericano de Misiología/Itinerarios Editorial (Colección Scripta autochtona, 15), Cochabamba, 2015, 231 p., bibliogr., ill. en coul. et en noir et blanc, cartes.

1 De la una y otro banda del río Paraguay: historia y etnografia de los itatines (siglos XVI-XVIII) é um dos mais recentes livros da prolífica antropóloga e historiadora Isabelle Combès. Como indica o título, o livro aborda a «etno-história » dos antigos Itatim, particularmente entre o início do século XVI e o final do século XVIII, quando esse " grupo étnico guaranifalante, antigamente assentado em ambas margens do rio Paraguai » desapareceu como tal (p. 12) e começou a dar origem a dois conjuntos atualmente muito mais conhecidos: os Kaiowá e Pai-Tavyterã do Brasil e do Paraguai respectivamente e os Guarayo da Bolívia.

2 Como afirma Graciela Chamorro no prólogo do presente trabalho, desde o Brasil ou Paraguai temos mais proximidade com a história dos antigos Itatim que viveram a leste do rio Paraguai, chamados nesse livro «Itatim orientais » (p. 7). No entanto, o livro de 
Combès é um convite para que conheçamos melhor a história daqueles Itatim que também viveram a oeste do mesmo rio (os «Itatim ocidentais ») e, sobretudo, um convite para que entendamos as estreitas relações que ambos conjuntos, orientais e ocidentais, mantiveram durante boa parte da época colonial até o início da época moderna, justamente quando a atual distinção entre Kaiowá, Pai-Tavyterã e Guarayo começou a se consolidar em detrimento do etnônimo Itatim.

Dito isto, é possível perceber que o objetivo da autora é « juntar duas metades » de uma mesma história (p.13): objetivo que, ao nosso ver, é ao mesmo tempo original e ambicioso. Original porque até o presente momento nenhuma pesquisa, seja ela histórica ou antropológica, tinha concretizado tal tarefa. Segundo a autora, "não existe na bibliografia uma história dos Itatim orientais em si » (p. 12-13). As únicas referências a eles são feitas en passant « nos primeiros capítulos dos trabalhos que tratam da história dos Kaiowá ou dos Pai-Tavyterã, ou bem em partes de estudos dedicados às missões jesuíticas » (p. 13). A situação dos estudos sobre os Itatim ocidentais é ainda mais grave, pois embora se conheça relativamente bem a de seus descendentes Guarayo a partir do século XIX, nenhum estudo se dedicou até agora a sua « história colonial » (p. 13).

4 Ambicioso também pela dificuldade de analisar e sistematizar fontes tão dispersas, oriundas de uma vasta região que os « azares ou caprichos da história » (p. 11) acabaram dividindo em três países (o Brasil, a Bolívia e o Paraguai) com línguas diferentes (espanhol e português). Ao nosso ver, ao enfrentar com coragem e rigor esse grande desafio, o objetivo da autora é propor uma alternativa metodológica para os estudiosos contemporâneos do mundo guarani. De alguma forma, o que Combès está sugerindo é que a falta de estudos que conectem a história dos Itatim orientais e ocidentais está intimamente relacionada a uma dificuldade maior dos antropólogos e historiadores: a de ultrapassar as barreiras geográficas e linguísticas de seus campos de interesses, e sobretudo quando se trata da história de povos indígenas antigos e «em geral recalcitrantes de se estabelecerem dentro dos limites administrativos»(p.12) dos Impérios e dos Estados.

5 Apesar de todo o pioneirismo e dificuldades relacionadas a sua pesquisa, é do nosso parecer que Combès é capaz de alcançar seu objetivo de forma cabal, propondo pistas de investigação muito pertinentes para o campo dos estudos guarani contemporâneos. Vejamos.

6 De la una y otra banda del río Paraguay está dividido em três partes (Una crónica itatín, Diccionario itatín e Documentos) precedidas de um prólogo. Como já apontamos, o prólogo é de autoria de Graciela Chamorro, autora que, diga-se de passagem, publicou recentemente importante livro sobre a História dos Kaiowá (Chamorro 2015).

7 Antes de comentar a primeira parte do livro (certamente a mais importante e interessante) gostaríamos de apontar algumas coisas sobre Diccionario itatim e Documentos, que compõem a segunda e a terceira parte do livro, respectivamente. No Diccionario Itatin a autora lista todos os nomes, topônimos, etnônimos, etc., encontrados nas fontes relativos aos antigos Itatim. Trata-se, de certa forma, de exercício bastante similar àquele que a autora já realizou anos atrás sobre o povoamento étnico ao redor da primeira cidade de Santa Cruz de la Sierra (Combès 2010). Documentos, por sua vez, é a transcrição integral ou parcial de 10 documentos cruciais para a pesquisa da autora. Ambas partes podem ser consideradas como uma espécie de anexo e são extremamente úteis para aqueles pesquisadores que pretendem incursionar de forma mais profunda na história dos antigos Itatim. 
Passemos agora à primeira parte do livro. Una crónica itatín corresponde a um estudo preliminar e está dividida em três capítulos. Neles, Combès se dedica a fazer uma espécie de arqueologia do termo Itatim, desde seu nascimento no início do século XVI até seu progressivo desaparecimento na passagem do século XVIII para o XIX. O que nos parece interessante nesse exercício é que a autora mostra que, antes de se transformar em um etnônimo, o termo Itatim fazia referência a topônimos, como a província de Itatim ou o porto de Itatim. A província de Itatim estava localizada a aproximadamente 100 léguas ao norte da cidade de Assunção; mais exatamente a leste do rio Paraguai, entre os rios Apa ao norte, o rio Tepotí ao sul e a vertente ocidental da Serra de Amambai. Teria sido somente pouco depois que a expressão teria passado de topônimo a etnônimo. Primeiro para se referir aos grupos de língua guarani que estavam localizados na margem ocidental do rio Paraguai (mais particularmente na atual Chiquitania boliviana). Só depois para se referir àqueles da província de Itatim propriamente dita (mais conhecidos nesse primeiro momento como « Guaranys » $\mathrm{e}$ « Carios »).

Entre muitas outras coisas, Combès sugere que não foi por acaso que os grupos de língua guarani da margem ocidental do rio Paraguai foram chamados Itatim. Na realidade, e essa nos parece ser a principal tese do livro, esses grupos estavam intimamente relacionados com os da província oriental de Itatim. Segundo a autora, essas relações eram bastante antigas, datando de migrações pré-hispânicas, e não somente das expedições empreendidas pelos primeiros conquistadores espanhóis (como Irala, Cabeza de Vaca, Nuflo de Chaves, etc.) que, guiados por vários grupos indígenas, muitos deles de língua guarani, partiram da cidade de Assunção em direção ao oeste, atrás das minas de metal dos Andes.

As poucas fontes existentes não permitam determinar com exatidão quando se iniciaram essas migrações ou esses deslocamentos pré-coloniais de la una y otra banda del río Paraguay. Contudo, essas mesmas fontes dão algumas pistas sobre o assunto, já que elas indicam, por exemplo, que vários grupos de língua guarani da margem oriental do rio Paraguai, entre eles os da província de Itatim, já haviam viajado em busca das minas incaicas antes mesmo das explorações de Alejo Garcia (1530) e Juan de Ayolas (1537). Informações similares também podem ser encontradas em algumas crônicas andinas: Garcilaso de la Vega y Sarmiento de Gamboa, por exemplo, mencionam a chegada de " chiriguanaes » (outro termo usado na época para se referir aos grupos de língua guarani da margem ocidental do rio Paraguai) na fronteira do império Inca de Yupanqui e Huayna Capac.

11 É importante ressaltar, no entanto, que Combès deixa claro que as migrações de grupos de língua guarani em direção ao oeste não estavam compostas apenas por grupos Itatim, embora essas sejam as migrações mais estudadas, e portanto mais conhecidas hoje. Baseando-se, entre outros, em estudos linguísticos de Wolf Dietrich, a autora sugere que a província de Itatim certamente funcionou como uma espécie de escala de um caminho muito mais amplo que conectava o oceano Atlântico às cordilheiras dos Andes. Essa sugestão é interessante na sua argumentação, já que ela aparece acompanhada de uma segunda: a de que os Itatim orientais e ocidentais foram conjuntos étnicos certamente formados por grupos de língua guarani variados e heterogêneos, justamente aqueles que ocupavam as regiões por onde passava esse vasto caminho. Em outras palavras, isso significaria dizer pelo menos duas coisas. Em primeiro lugar, que os atuais Guarayos, Kaiowá e Pai-Tavyterã provavelmente não sejam descendentes unicamente dos Itatim, mas também de outros grupos da mesma família linguística. Em segundo lugar, que os 
Itatim que migraram em direção ao oeste participaram das gêneses de vários outros grupos de língua guarani, e não somente da dos atuais Guarayos.

A hipótese da autora sobre o processo de etnogêneses dos Itatim, e seus descendentes atuais, me parece extremamente importante do ponto de vista teórico. Além da virtude de transformar complicados processos de etnogêneses em histórias simples (virtude que já virou marca registrada da sua vasta obra), Combès também é capaz de acompanhar, com muito rigor e meticulosidade, as complicadas e emaranhadas trajetórias dos inúmeros gentilícios indígenas que povoaram as terras baixas sul-americanas na época colonial e moderna, e isso sem nunca cair naquilo que poderíamos chamar de " armadilha étnica ». A capacidade de Combès de traduzir processos complicados em histórias simples não se reduz apenas ao uso consciente que ela faz de uma linguagem clara, agradável e transparente, acessível, ademais, a um público muito mais amplo de não especialistas. Essa capacidade é, antes de tudo, o resultado ou a consequência de uma postura teórico-metodológica consistente baseada no tratamento rigoroso dado às mais diversas fontes históricas e etnográficas. A leitura que a autora faz dessas fontes faz com que, embora ela reconheça a existência de uma origem comum entre esses grupos, ela não comparta aquela visão ingênua, tão presente nos estudos guarani, que considera que a única diferença entre os antigos Itatim (orientais e ocidentais) e os atuais Kaiowá, PaiTavyterã e Guarayo seja apenas de ordem onomástica ou etnonímica.

Recordemos que Combès intitula a introdução de seu livro En el corazón de América del Sur. Essa expressão foi retomada do naturalista Francis de Castelnau, que a usou na metade do século XIX para se referir à região por onde passou (antiga província brasileira de Mato Grosso, Chiquitania boliviana e norte do Chaco boreal), e que também é a região onde viviam os antigos Itatim e onde vivem atualmente parte de seus descendentes, os já mencionados Kaiowá, Pai-Tavyterã e Guarayo. No entanto, na obra de Combès, além desse sentido geográfico, a expressão ganha um significado conceitual relacionado com sua interpretação dos processos de formação étnica. Segundo ela, antes dos tratados internacionais que traçaram as fronteiras entre os antigos impérios ibéricos e o atuais Estados do Brasil, Paraguai e Bolívia, a região representava uma verdadeira «área cultural » (p.11). Ou seja, uma região atravessada de « contatos [...], trocas, alianças interétnicas [...] que nos obriga a considerá-la como um todo » (p. 11). De fato, um dos maiores aprendizados que ficam após a leitura de Monumenta Itatinorum, como o livro ficou conhecido entre aqueles que acompanharam seu processo de gestação (p. 10), é que o passado, o presente e o futuro dos grupos de língua guarani da região não podem ser pensados como um fenômeno étnico isolado, já que esses grupos estão inseridos em um contexto político, cultural e social regional muito mais amplo dentro do qual os processos étnicos tomam forma.

\section{BIBLIOGRAFIA}

CHAMORRO Graciela

2015, História Kaiowa Das origens aos desafios contemporâneos, Nhanduti, São Bernardo do Campo. 
coMBÈs Isabelle

2010, Diccionario étnico. Santa Cruz la Vieja y su entorno en el siglo XVI, Itinerarios/ILAMIS (Scripta Autochtona, 4), Cochabamba.

\section{AUTORES}

\section{PABLO BARBOSA}

Pós-doutorando, FAPERJ (PPGAS, MN, UFRJ) 